\title{
Thoracic spine osteophyte causing dysphagia
}

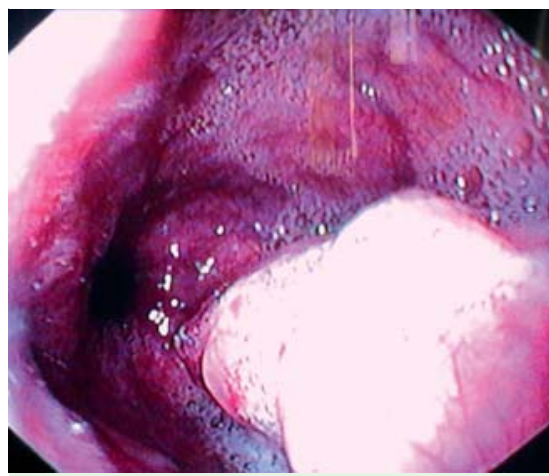

Fig. 1 Polypoid lesion in the esophagus.

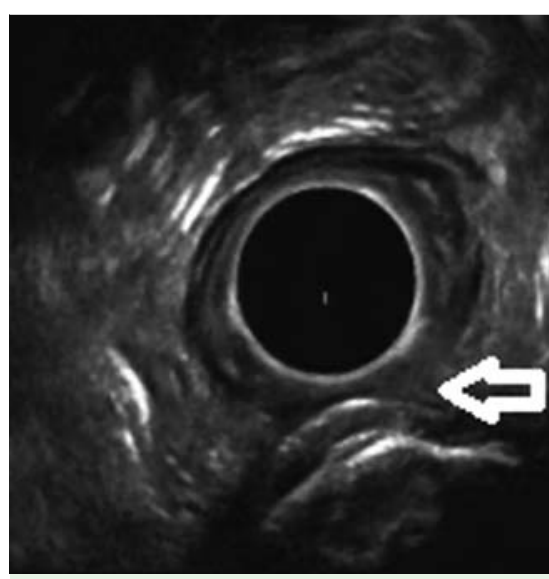

Fig. 2 Endoscopic ultrasonography showing erosion of posterior esophageal wall by vertebra (arrow).

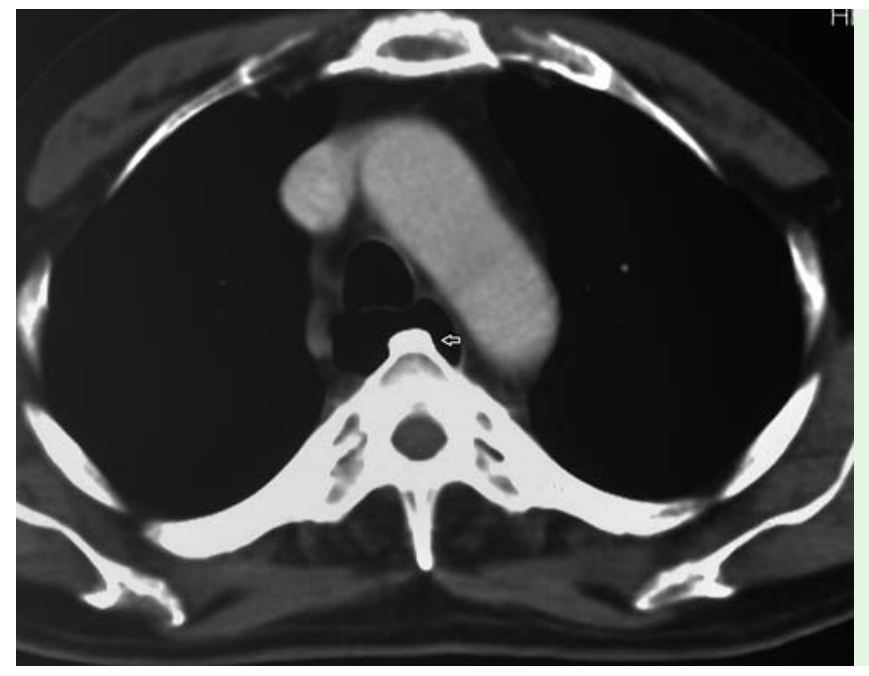

Fig. 3 Contrast-enhanced computed tomography showing erosion into the posterior esophageal wall by vertebra (arrow).



Fig. 4 Contrast-enhanced computed tomography with positive oral contrast in esophagus could not demonstrate the lesion in the posterior esophageal wall.
A 65-year-old man, a chronic smoker and alcoholic with a diagnosed adenocarcinoma of the antrum of the stomach, was being further investigated because of dysphagia; endoscopic examination at the referring center showed a polypoid lesion in the mid esophagus. Positron emission tomography (PET) revealed increased uptake of fluorodeoxyglucose in this esophageal lesion. The possibility of a metastasis to the esophagus from the gastric malignancy was considered. However, biopsy from the esophageal lesion revealed features of chronic inflammation. A repeat gastroscopy was done and a polypoid lesion was observed in the mid esophagus (๑ Fig. 1). Histopathological examination of the biopsy specimen from this lesion again revealed features of chronic inflammation. Contrast-enhanced computed tomography (CECT) of the chest with intravenous and a positive oral contrast revealed a dilated esophagus.

Radial endoscopic ultrasound examination of the esophagus revealed that the vertebral column was eroding into the posterior esophageal wall at the site of the lesion noted on endoscopy ( $\bullet$ Fig. 2). A repeat chest CECT, this time without oral contrast, showed that an anterior osteophyte from the thoracic vertebra was eroding into the esophagus ( $\bullet$ Fig. 3). It had not been possible to diagnose it in the previous CECT as during that procedure positive oral contrast was given which obscured the vertebral erosion into the esophagus
( Fig.4). A barium esophagogram also documented indentation of the posterior wall of the esophagus by a thoracic vertebra ( $\bullet$ Fig. 5).

Anterior osteophytes can occasionally impinge on the anteriorly located esophagus and can cause dysphagia [1-4]. This commonly involves the hypopharynx or the cervical esophagus [1-4]. Involvement of the thoracic esophagus is very rare because the thoracic esophagus is a relatively mobile structure in the posterior mediastinum that can be displaced without being compressed [5].

Endoscopy_UCTN_Code_CCL_1AB_2AC_3AH

Competing interests: None 

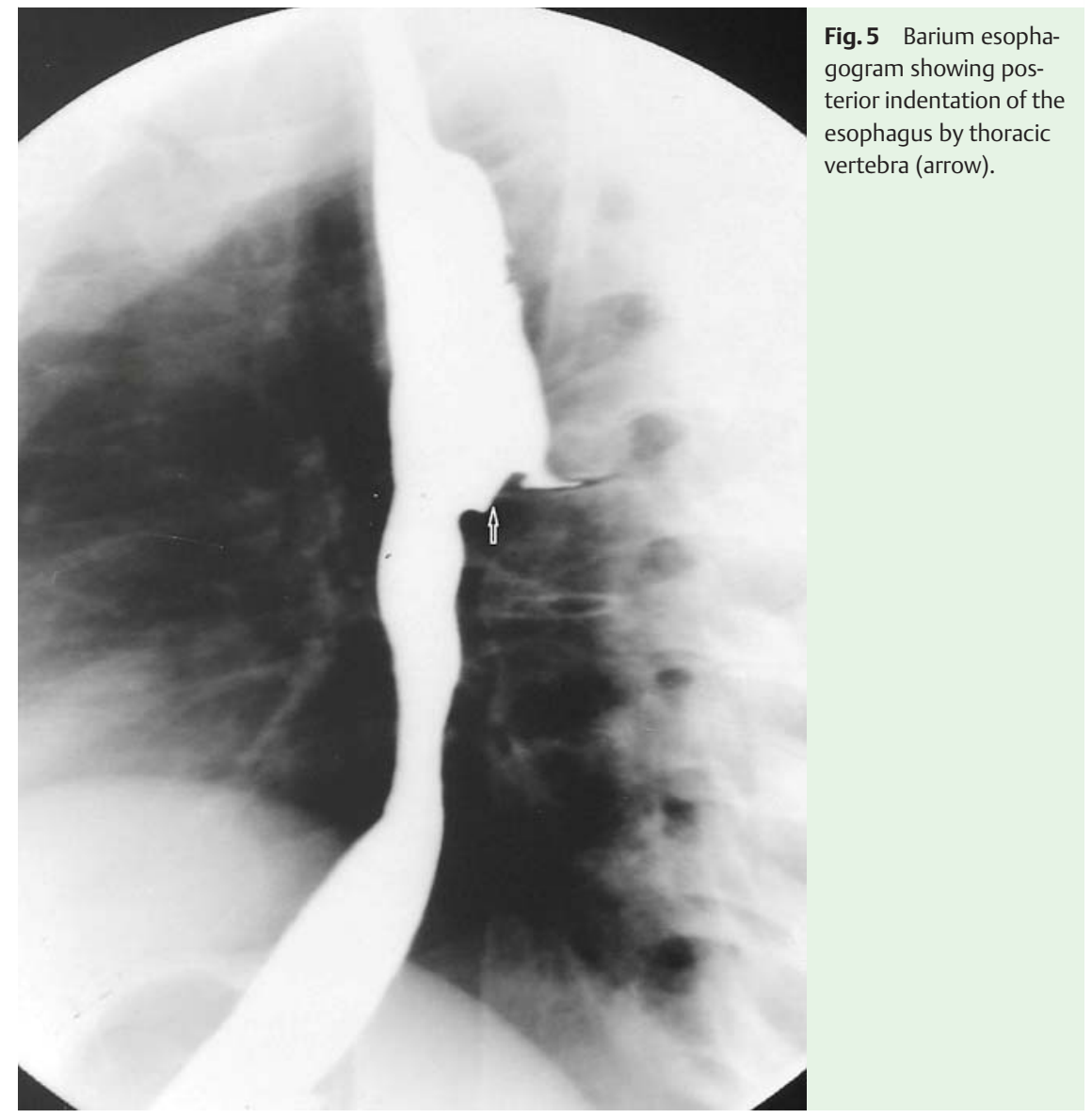

\section{S. S. Rana', D. K. Bhasin', C. Rao',} R. Gupta ${ }^{2}$, B. Nagi ${ }^{1}$, K. Singh ${ }^{1}$

${ }^{1}$ Department of Gastroenterology, Postgraduate Institute of Medical Education and Research, Chandigarh, India

2 Department of Surgery, Postgraduate Institute of Medical Education and Research, Chandigarh, India

\section{References}

1 Hilding DA, Tachdjian MO. Dysphagia and hypertrophic spurring of the cervical spine. N Engl J Med 1960; 263: 11 - 14

2 Resnick D, Shaul SR, Robins JM. Diffuse idiopathic skeletal hyperostosis (DISH): Forestier's disease with extraspinal manifestations. Radiology 1975; 115: 513-524

3 Lin HW, Quesnel AM, Holman AS et al. Hypertrophic anterior cervical osteophytes causing dysphagia and airway obstruction. Ann Otol Rhinol Laryngol 2009; 118: $703-707$

4 Seidler TO, Pèrez Alvarez JC, Wonneberger K et al. Dysphagia caused by ventral osteophytes of the cervical spine: clinical and radiographic findings. Eur Arch Otorhinolaryngol 2009; 266: 285-291

5 Underberg-Davis S, Levine MS. Giant thoracic osteophyte causing esophageal food impaction. AJR Am J Roentgenol 1991; 157: 319 320

\section{Bibliography}

DOI http://dx.doi.org/

10.1055/s-0031-1291501

Endoscopy 2012; 44: E19-E20

(c) Georg Thieme Verlag KG

Stuttgart · New York

ISSN 0013-726X

\section{Corresponding author}

S. S. Rana, MD

Department of Gastroenterology

Postgraduate Institute of Medical Education and Research (PGIMER)

Chandigarh

160012 India

Fax: 91-172-2744401

drsurinderrana@yahoo.co.in

sonalisurinder@yahoo.co.in 